Ecology

\section{Lunar cycles in lake plankton}

\section{from Geoffrey Fryer}

RHYTHMIC behaviour is an almost universal attribute of animals, the most familiar example being that of activity by day and resting by night, or vice versa. A cycle related to the movements of heavenly bodies is also shown by many intertidal animals, the lunar cycle being associated with that of the tides. These rhythms are sometimes intrinsic (or endogenous): they continue, at least for a time, when the cycle is broken experimentally. More puzzling are rhythms associated with the lunar cycle shown by certain freshwater animals, of which only a few cases are known. Some African insects with aquatic larvae emerge only at certain phases of the Moon. Maciej Gliwicz (Ecology 67, 883; 1986) now demonstrates a lunar cycle in planktonic crustaceans, a cycle that is not intrinsic but is imposed on the organisms by a predator. The study reveals a fascinating set of ecological relationships; it remains to be seen whether as yet undiscovered adaptations are involved.

In the Cahora Bassa Reservoir, Zambezi Valley, Mozambique, four cladocerans (a ctenopod and three anomopods; see figure) and two copepods (a calanoid and a cyclopoid) show changes in numerical abundance that are clearly synchronized with the lunar cycle. Such a pattern could only be revealed by frequent sampling. Monthly sampling might greatly over- or underestimate numbers, depending on the starting date, and might fail to detect the very considerable fluctuations in population size.

How can this cycle be explained? Birth rates are such that the fluctuations cannot be attributed to changes in the fecundity of these rapidly reproducing organisms. Maximum death rates, however, occur around full Moon and changes in death

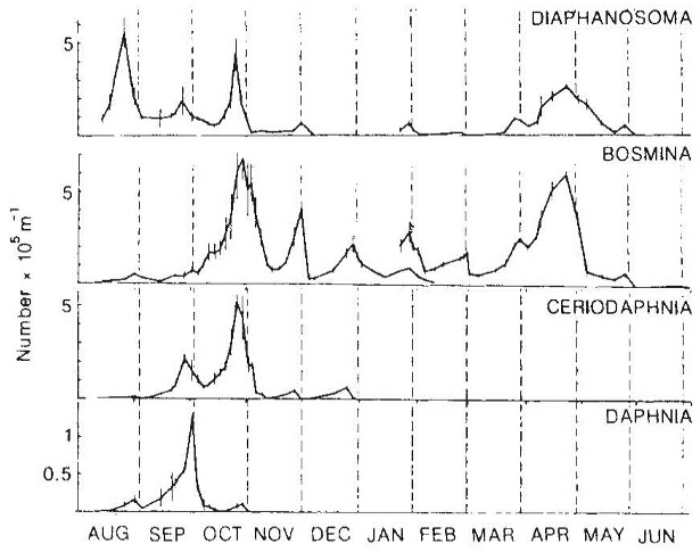

Changes in population size of cladocerans in relation to the lunar cycle in Cahora Bassa Reservoir. Vertical broken lines, full Moon. rates are clearly responsible for the fluctuations. The culprit is Limnothrissa miodon, a sardine-like clupeid fish native to Lake Tanganyika. Introduced to Lake Kariba, it has moved downstream and colonized Cahora Bassa. It feeds avidly on planktonic crustaceans, and calculations show that its depredations can account for even the most drastic declines observed in its planktonic prey.

There are changes in abundance of Limnothrissa adults, evidently short-lived in Cahora Bassa; annual changes in zooplankton abundance are related to these, but lunar fluctuations are not. Lunar fluctuations are caused by changes in feeding efficiency of the predator at different phases of the Moon. Limnothrissa feeds intensively throughout the night at full Moon, following the vertically migrating plankton to the surface: on moonless nights it is too dark for efficient hunting, so the predator disperses over a wide range of depths. Diaphanosoma and Ceriodaphnia begin to decline a few days before full Moon, as one might expect. In Bosmina and Daphnia, however, maximum death rates tend to occur after full Moon. Why should this be?

Gliwicz finds that stomachs of Limnothrissa are always fuller soon after full Moon than just before it, despite the similar light intensities and the fact that plankton is always more abundant before than after full Moon. Feeding intensity depends on the time of moonrise: before full Moon there is moonlight as soon as the sun sets and the plankton does not rise very near the surface; after full Moon there is complete darkness for between one and three hours, during which time the plankton ascends to the surface. When the full moon rises, its appearance is particularly sudden in Cahora Bassa, which lies in a gorge. Plankton that has previously risen to near the surface is thus suddenly exposed to predation by Limnothrissa and is heavily cropped. Daphnia and Bosmina are apparently particularly vulnerable to this trap. This is the first time that such lunar cycles have been demonstrated, but Gliwicz thinks he can detect others in published data on planktonic Cladocera in temperate lakes - cycles probably overlooked at the time as inherent sampling variations.

Since the classical work of Hrbáček (Verh. int. Ver.
Limnol. 13, 394; 1961) and of Brooks and Dodson (Science 150, 28; 1965) which shows how the introduction of a predator can alter the species composition of a plankton community, predation has been shown to have profound selective effects on the size, transparency and even on the gross morphology of planktonic anomopod cladocerans. The avoidance of predators has also long been considered to be a possible explanation of the phenomenon of vertical migration, and seems in some cases certainly to be involved. But dramatic fluctuations in abundance related to the lunar cycle suggest that planktonic crustaceans have not been able to evolve a complete response to increased predation at the time of full Moon. Avoidance of the surface waters on moonlit nights certainly reduces the effects of predation, but the trap set by the timing of sunset and moonrise is more difficult to detect and avoid.

Are such problems real or do they exist only in the human mind? Planktonic animais certainly suffer enormous mortality when caught in the Moon trap - yet they survive, and in sufficient numbers to build up their populations again within a lunar month. Fecundity may be the adaptive mechanism here: it might be advantageous to purchase grazing rights in rich pastures at the high price of periodic heavy payments.

The patterns of emergence of two African insects may be relevant to this hypothesis. In Lake Victoria the mayfly Povilla adusta emerges with a sharp peak of abundance on the second to fourth nights after full Moon (Hartland-Rowe, R. Revue zool. Bot. afr. 63, 185; 1958); in Lake Bangweulu the midge Chironomus brevibucca does so on the third to fifth nights (Fryer, G. Bull. ent. Res. 50, 1; 1959). Such synchronized emergence has the obvious advantage of facilitating the finding of mates. Swarming and spawning of marine organisms, essentially polychaetes, with similar lunar rhythms takes place at similar Moon ages. P. Korringa (Mem. geol. Soc. Am. 67, 917; 1957) has shown how marine animals might use moonlight to time and to synchronize their maturation, and this explanation fits the observed emergence times of $P$. adusta and $C$. brevibucca. In both species emergence takes place very near the phase of the Moon when the insects are most vulnerable to predation, and both are eaten extensively. Again, however, these species may find it advantageous to pay this price to achieve synchronized emergence at a convenient phase of the Moon. In the case of $C$. brevibucca, the numbers emerging are so immense that even heavy predation is trivial.

Geoffrey Fryer is at the Windemere Laboratory of The Freshwater Biological Association, Ambleside, Cumbria LA22 OLP, UK. 